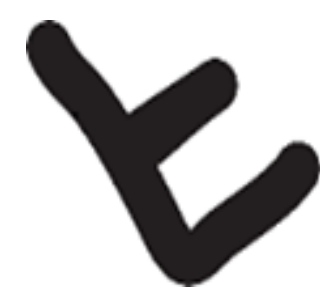

REVISTA DE ESTUDIOS E INVESTIGACIÓN EN PSICOLOGÍA Y EDUCACIÓN

ISSN: 1138-1663; eISSN: 2386-7418

2020, Vol. 7, No. 2, 104-114.

DOI: https://doi.org/10.17979/reipe.2020.7.2.5782

\title{
Teoria das situações didáticas gamificadas: um esboço detalhado no ensino da sequência de Padovan
}

\author{
Theory of gamified didactic situations: a detailed outline in teaching the \\ Padovan sequence
}

\begin{abstract}
Darkson Fernandes da Costa (iD*, Rosalide Carvalho de Sousa (D)*, Renata Passos Machado Vieira (D)*, Francisco Regis Vieira Alves (D)*, Juscileide Braga de Castro (D**, Gilvandenys Leite Sales (D)*

*Instituto Federal de Educação, Ciências e Tecnologia do Ceará, **Universidade Federal do Ceará
\end{abstract}

\begin{abstract}
Resumo
Este trabalho possui o objetivo de apresentar uma sistematização de saberes para uma possível aplicação da gamificação no ensino da Matemática, fundamentado nas etapas do percurso metodológico da Teoria das Situações Didáticas (TSD) como metodologia de ensino. Para tanto, utilizou-se como base de metodologia de pesquisa as duas fases iniciais da Engenharia Didática (ED), referentes às análises preliminares e a priori. Ademais, usou-se como exemplo o assunto específico da extensão da sequência de Padovan para índice inteiro não positivo, com o enfoque em alunos no nível de graduação. Nesse sentido, o ponto central do trabalho não direciona-se para uma análise dos dados de uma aplicação em si, mas da demarcação de elementos representativos que pleiteiam uma sistematização e acumulação de saberes teóricos/científicos, para a formulação de uma proposta didática e metodológica no ensino da Matemática com a interação das estratégias de gamificação, TSD e ED.
\end{abstract}

Palabras chave: gamificação; ensino superior; matemática; formação do professor de matemática; resolução de problemas

\begin{abstract}
The aim of this study is to create a systematisation of knowledge for the possible application of gamification in the teaching of Mathematics, based on the Theory of Didactical Situations (TDS) as a teaching methodology. The preliminary and a priori analysis phases of Didactical Engineering (DE) are used as the basis for the research methodology, taking as a case study the teaching to students at undergraduate level of
\end{abstract}

[Autores viculados ao Programa de Pós-Graduação em Ensino de Ciências e Matemática (PGECM), com subsídio da Fundação Cearense de Apoio ao Desenvolvimento Científico e Tecnológico (Funcap) referente ao autor, bolsista Darkson Fernandes da Costa]

Darkson Fernandes da Costa (Dhttps://orcid.org/0000-0002-8304-0723, Rosalide C. Sousa Dttps://orcid.org/0000-0002-8059-1159, Renata Vieira Dhttps://orcid.org/0000-0002-1966-7097, Francisco R. V. Alves (Dhttps://orcid.org/0000-0003-3710-1561, e Gilvandenys L. Sales Dhttps://orcid.org/0000-0002-6060-2535: Instituto Federal de Educação, Ciências e Tecnologia do Ceará Av. Treze de Maio, 2081 - Benfica, Fortaleza - CE, 60040-531 Brasil.

Juscileide Braga de Castro (Dhttps://orcid.org/0000-0002-6530-4860: Universidade Federal do Ceará - Av. da Universidade, 2853 Benfica, Fortaleza - CE, 60020-181, Brasil.

Correspondência relativa a este artículo: Darkson Fernandes da Costa - darksonifce@gmail.com 
the extension of the Padovan sequence to a non-positive whole index. The main objective of the research is not, therefore, to analyse the data of the application itself, but to identify the theoretical/scientific knowledge elements that require systematisation and accumulation, in order to formulate a didactic and methodological proposal for the teaching of mathematics that combines gamification strategies, TDS and DE.

Keywords: gamification; higher education; mathematics; mathematics teacher training; problem solving

Diferenças culturais entre gerações e o engajamento dos alunos em sala de aula concretizam-se como um dos desafios para o corpo docente das instituições de ensino. Para Alves (2015) às novas gerações precisam observar se o que fazem é realmente relevante para o sistema em que estão inseridos. Nesse sentido, vale identificar estratégias de engajamento que podem ser implementadas com metodologias de ensino que utilizem da participação dos alunos nas práxis em sala de aula.

Silva e Sales (2017), identificaram evidências do potencial da gamificação para motivar, atrair e engajar os indivíduos em atividades em sala de aula. Contudo, percebe-se a necessidade de demarcar elementos que defendem uma sistematização de saberes teóricos/científicos balizados na interação entre gamificação e os diferentes percursos metodológicos, pois a técnica de gamificação vem sendo utilizada com relativo sucesso no marketing e na organização interna das empresas (Gomes e Silva, 2018; Ribeiro Jr. et al., 2017; Silva et al., 2019).

As pesquisas na área de gamificação no ensino tem um caráter relativamente novo, impulsionado pelo desenvolvimento tecnológico acelerado e a democratização do acesso à internet. Segundo Kapp (2012), a gamificação trata-se do uso de elementos, mecânicas e estratégias pertencentes aos games para motivar, engajar e atrair a atenção das pessoas com o intuito de promover o envolvimento e a motivação dos indivíduos. Nesse sentido, essa técnica relaciona-se com os problemas ou atividade do cotidiano através da implementação dos elementos de game ao ter como meta estimular a participação dos indivíduos.

O percurso metodológico da Teoria das Situações Didáticas (TSD) tem como objetivo exteriorizar os conhecimentos teórico/investigativo do aluno ao deparar-se com situações conflitivas no decorrer das fases de ação, formulação, validação e institucionalização (Brousseau, 1986). No entanto, observa-se que somente a TSD não contempla características que impulsionam, estimulam e atraem os alunos para participarem ativamente de todas as fases propostas durante a aula. Nesse sentido, uma possível solução para isso é desenvolver estratégias em que a TSD e a gamificação estejam alinhadas.

Pesquisas que buscam abordar as formas de aplicação da técnica de gamificação em parceria com sequências didáticas no ensino vem aumentando nas últimas décadas (Silva e Sales, 2018). Para que ocorra uma concordância entre os elementos de game e qualquer estratégia metodológica de ensino, o docente deverá planejar suas etapas didáticas levando em consideração o conteúdo selecionado, o nível cognitivo dos alunos e os elementos de game que podem ser utilizados, em outras palavras, realizar uma gamificação didática.

Nesse sentido, o presente trabalho trata-se de um delineamento para o planejamento metodológico sem uma aplicação e coleta prática dos dados no ensino da Matemática para o nível dos alunos de graduação. Vale relatar que a pesquisa foi organizada na estrutura da Engenharia Didática (ED), em que se utilizou as duas primeiras fases (análise preliminar e análise a priori), sem o aprofundamento das etapas de experimentação e validação, tornando-se assim um artigo puramente descritivo.

Para o ensino da Matemática utilizou-se como exemplo o assunto específico das situações conflitivas voltados para a extensão da sequência de Padovan para índice inteiro não positivo. Tomará como base os conhecimentos prévios dos alunos referentes à outra sequência comumente abordada em livros de História da Matemática, porém mais conhecida, a sequência de Fibonacci. Além disso, os estudantes deverão ter uma base em Álgebra Linear e demonstração por passos indutivos, visto que será investigada a forma matricial desses números voltados ao processo de extensão.

Por tratar do objeto matemático referente à sequência de Padovan, a pesquisa poderá ser aplicada em curso no nível de graduação, pois o assunto de sequências lineares ocorrem de forma mais expressiva na matriz curricular de cursos superiores de Matemática. 
Com base no que foi abordado, a presente proposta possui como objetivo, apresentar uma sistematização de saberes para uma possível aplicação da gamificação no ensino da sequência de Padovan para índice inteiro não positivo com base no público alvo dos alunos no nível de graduação, fundamentado nas fases da TSD como metodologia de ensino e nas duas primeiras etapas da ED como metodologia de pesquisa. Vale ressaltar que as duas últimas fases da ED (experimentação, análise a posteriori e validação) não serão afetadas.

Nas próximas seções serão abordados o referencial teórico da gamificação, TSD e ED. Em seguida, na metodologia, será apresentado as etapas de concepção e análise a priori da ED e o passo metodológico do uso da gamificação nas situações conflitivas. Por fim, serão apresentadas as considerações finais, em que será relatado as concepções dos autores no alinhamento da gamificação, TSD e ED, assim como, propostas de trabalhos futuros.

\section{Gamificação}

O estudo da gamificação é comumente direcionado para o engajamento e a motivação dos indivíduos em atividades do cotidiano ao se utilizar, para isso, as características/elementos encontrado nos games (Costa, Monteiro, Castro, Júnior e Sales, 2019). Inicialmente a gamificação obteve destaque no marketing, como estratégia de fidelização de clientes em aplicações para a web, devido seu bom desempenho para influenciar pessoas e motivá-las.

A gamificação vem sendo implementada como estratégia em atividades mais participativa dos alunos em sala de aula (Silva et al., 2019). Contudo, por se tratar de uma estratégia ainda principiante, evidencia-se poucas pesquisas, esclarecendo como se aplicar tal artifício (Ramos e Marques, 2017). No trabalho realizado por Costa et al. (2019), fundamentado em McGonigal (2017), foi esclarecido que alguns elementos da gamificação caracterizam-se como essenciais em qualquer sistema gamificado, a saber: i) regras; ii) voluntariedade; iii) objetivos e iv) feedbacks. Além disso, para que um sistema gamificado seja verdaeiramente motivador em sala de aula, ele precisa ser desafiador.

As estratégias utilizadas para o desenvolvimento dos desafios devem ser levados em consideração com o devido respeito, visto que o principal intuito da gamificação nas aulas é manter os alunos envolvidos. Nesse sentido, convenciona-se um olhar mais apurado para as teorias motivacionais sobre os níveis que os desafios devem conter e a relação com as habilidades dos alunos, identificado na teoria do Flow por Csikszentmihalyi (1999).

A teoria do Flow pretende explicar os motivos que levam os indivíduos a ficarem completamente envolvidos em atividades que não proporcionam retorno material de imediato (Csikszentmihalyi, 1999; Silva et al., 2019). A ideia empregada nessa teoria explica que para o indivíduo manter-se em um estado de profunda concentração em determinadas atividades, é preciso que essa atividade esteja em equilíbrio com as suas habilidades. Se a capacidade do indivíduo for muito maior que o nível do desafio, o sujeito terá a sensação de tédio. Se o nível do desafio for muito maior que as competências, ele terá ansiedade. Por isso, convenciona-se que as desafios iniciais devem conter um nível proporcional às habilidades dos alunos. Iniciando-se por um desafio de nível baixo e aumentando progressivamente, conforme os ganhos de agilidade/habilidade forem se desenvolvendo.

Para a gamificação do percurso metodológico fundamentado na TSD, levou-se como base os elementos esclarecidos por Costa et al. (2019) para atividades em sala de aula e as oito unidades de gamificação, identificado por Chou (2015), em que foram assinalados os principais motivos que podem levar as pessoas a realizarem certas tarefas detectadas em alguns games (Tabela 1), identificados pelo autor como Core Drive, que são: 1) Significado épico; 2) Desenvolvimento e realização; 3) Capacidade de criatividade e feedback; 4) Propriedade e posse; 5) Influência social e parentesco; 6) Escassez e impaciência; 7) Imprevisibilidade e curiosidade; e 8) Perda e prevenção.

No trabalho de Chou (2015) foi realizado uma pesquisa para identificar e desenvolver estratégias, conforme as oito unidades, com isso, implementá-los com o contexto da gamificação para diversas situações. Esta pesquisa pretende implementá-los no ensino de matemática, conforme a adaptação de alguns conceitos. 


\section{Tabela 1}

Unidades principais da gamificação fundamentadas em Chou (2015)

\begin{tabular}{|c|c|c|}
\hline Unidades da gamificação & Significado & Contexto do ensino \\
\hline Significado Épico & $\begin{array}{l}\text { É a vontade de fazer-se presente em } \\
\text { situações que proporcionam resultados } \\
\text { maiores para as ações dos indivíduos. }\end{array}$ & $\begin{array}{l}\text { O aluno torna-se o herói ao participar e } \\
\text { envolver-se com as situações gamificadas } \\
\text { em sala de aula. }\end{array}$ \\
\hline $\begin{array}{l}\text { Desenvolvimento e } \\
\text { realização }\end{array}$ & $\begin{array}{l}\text { É a vontade de progredir, desenvolver } \\
\text { habilidades e superar os desafios. Em outras } \\
\text { palavras, é o prazer de se realizar } \\
\text { descobertas autênticas. }\end{array}$ & $\begin{array}{l}\text { Os alunos sentem a sensação de realização } \\
\text { ao resolver bons desafios e, com isso as } \\
\text { conquistas tornam-se motivadoras. }\end{array}$ \\
\hline $\begin{array}{l}\text { Capacidade de criatividade } \\
\text { e feedback }\end{array}$ & $\begin{array}{l}\text { É a identificação de que o que se faz possui } \\
\text { um resultado significativo. Trata-se da } \\
\text { sensação de progresso nas atividades. }\end{array}$ & $\begin{array}{l}\text { Os aluno deve receber feedback constante } \\
\text { para sentirem uma evolução na sua } \\
\text { aprendizagem e no caminho para se concluir } \\
\text { um objetivo. }\end{array}$ \\
\hline Propriedade e posse & $\begin{array}{l}\text { É a identificação de que possui algo valioso } \\
\text { para ele e para o grupo em que encontra-se } \\
\text { inserido. }\end{array}$ & $\begin{array}{l}\text { O aluno sente-se motivado ao tornar-se } \\
\text { especialista em um determinado } \\
\text { conceito/assunto, fazendo-se um aluno } \\
\text { participativo por ser importante no grupo } \\
\text { em sala de aula. }\end{array}$ \\
\hline $\begin{array}{l}\text { Influência social e } \\
\text { realização }\end{array}$ & $\begin{array}{l}\text { As relações sociais contêm um papel } \\
\text { importante nas ações dos indivíduos, } \\
\text { movidos por: aceitação, companheirismo, } \\
\text { participação, competição e outros. }\end{array}$ & $\begin{array}{l}\text { O interesse dos alunos por atividades e } \\
\text { assuntos em que seus colegas se interessam } \\
\text { é muito forte. Nesse sentido, não se pode } \\
\text { ignorar essa variável na sala de aula, o } \\
\text { intuito é impulsioná-la cada vez mais. }\end{array}$ \\
\hline Escassez e impaciência & $\begin{array}{l}\text { É a vontade de ser dono de algo que não se } \\
\text { tem ainda, como exemplo: prêmio, cargo, } \\
\text { reconhecimento, resultados e outros. }\end{array}$ & $\begin{array}{l}\text { O fato dos alunos não terem conquistas e } \\
\text { reconhecimento, em relação à situações } \\
\text { conflitivas pode fazê-lo pensar nisso até } \\
\text { conseguir. }\end{array}$ \\
\hline $\begin{array}{l}\text { Imprevisibilidade e } \\
\text { curiosidade }\end{array}$ & $\begin{array}{l}\text { É o prazer realizado ao se deparar com } \\
\text { situações inesperadas. Conforme as } \\
\text { situações inesperadas acontecem os } \\
\text { indivíduos tendem a pensar sobre o que vem } \\
\text { a seguir. }\end{array}$ & $\begin{array}{l}\text { Os alunos optam por coisas imprevisíveis } \\
\text { que podem acontecer em sala de aula. Como } \\
\text { o resultado de um experimento, uma prática } \\
\text { social ou até uma história. }\end{array}$ \\
\hline Perda e prevenção & $\begin{array}{l}\text { É a motivação para se evitar algo negativo } \\
\text { ou a perda de todo o trabalho realizado. }\end{array}$ & $\begin{array}{l}\text { Alguns alunos, tendem a não desistir de } \\
\text { certas atividades, por conta da sensação de } \\
\text { perder todo o tempo gasto ou a proximidade } \\
\text { do objetivo esclarecido no contrato didático. }\end{array}$ \\
\hline
\end{tabular}

$\mathrm{Na}$ Tabela 1, as unidades são exemplos de motivação extrínseca. A motivação intrínseca significa a satisfação espontânea em realizar atividades por possuir prazer em realizá-las. Assim, essas unidades podem despertar motivação intrínseca, conforme a interação que elas proporcionam com os assuntos e com os alunos. Evidencia-se este tipo de situação em sala de aula, quando os alunos têm uma interação maior com as aulas, simplesmente por gostar do assunto, o que possibilita a participação por conta própria.

A motivação extrínseca relaciona-se com as recompensas que a realização das atividades podem proporcionar, assim como, as perdas por não realizá-las. Segundo Leal, et al. (2013), a vontade de realizar determinadas tarefas não vem do fazer em si, mas das consequências produzidas pelas atividades. Logo, o comportamento dos indivíduos, na motivação extrínseca encontram-se diretamente relacionados com os estímulos/consequências provenientes de realizá-las ou não.

Para que ocorra a gamificação em sala de aula, não se torna obrigatório o uso de todas essas unidades apresentadas por Chou (2015), visto que o principal intuito é proporcionar o desenvolvimento de materiais/organização em uma seção didática ao favorecer a participação, a motivação e o engajamento do aluno. Nessa perspectiva, será implementado as unidades em conformidade com os passos da TSD, os objetivos da aula e a interação com situações problema, propostas e categorizadas pela ED. 


\section{Teoria das situações didáticas (TSD)}

A TSD é um modelo teórico desenvolvido por Brousseau (1986) que propicia a compreensão dos diversos fenômenos abordados na aprendizagem da matemática, bem como o envolvimento da tríade professor, aluno e conhecimento na tentativa de promover atividades voltadas para o ensino de um conteúdo específico. De acordo com Pais (2015, p. 48), é importante ressaltar que “[...] o significado do saber matemático escolar deve ser elaborado em sintonia com a situação didática. A partir do momento em que os conteúdos são trabalhados, as atividades propostas aos alunos definem o tipo de situação".

Assim, para analisar essa relação entre o saber matemático e as atividade de ensino, a TSD se decompõe em quatro fases que de acordo com Pais (2015, pp. 51-53), elas são assim caracterizadas:

1. Situação de ação é aquela em que o aluno realiza procedimentos mais imediatos para a resolução de um problema, resultando na produção de um conhecimento de natureza mais operacional e intuitiva do que teórica. Nessa situação há sempre o predomínio quase que exclusivo do aspecto experimental do conhecimento.

2. Situação de formulação é aquela em que o aluno passa a utilizar, na resolução de problemas, algum esquema de natureza teórica contendo um raciocínio mais elaborado do que um procedimento experimental e, para isso, torna-se necessário aplicar informações anteriores.

3. Situação de validação são aquelas em que os alunos já utilizam o mecanismo de prova e o saber já elaborado por ele passa a ser usado com uma finalidade de natureza essencialmente teórica. Este tipo de situação está relacionado ao plano de argumentação racional e, portanto, está voltada para a questão da veracidade do conhecimento.

4. Situação de institucionalização têm a finalidade de buscar o caráter objetivo e universal do conhecimento estudado pelo aluno. Sob o controle do professor, é o momento onde se tenta proceder a passagem do conhecimento, do plano individual e particular, à dimensão histórica e cultural do saber científico. Por meio dessas situações, o saber passa a ter um estatuto de referência para o aluno, extrapolando o limite do subjetivo.

Assim, as situações didáticas apresentadas neste artigo descrevem uma trajetória de ensino de certas propriedades do processo de extensão da sequência de Padovan para o campo dos números inteiros não positivos. Seguem-se os procedimentos necessários e as possibilidades de estratégias para a realização das situações-problema, estruturadas pela TSD.

\section{Engenharia didática}

A ED possibilita ao professor um planejamento de situações didáticas voltadas para aplicação em sala de aula. Segundo Artigue (1995), trata-se de um trabalho didático comparável ao trabalho de um engenheiro ao realizar um projeto, baseia-se nos conhecimentos científicos de seu domínio, submetendo-se a um controle científico, ao mesmo tempo que se vê obrigado a trabalhar com objetos muito mais complexos do que os depurados pela ciências: problemas estes que a ciências não quer ou não pode resolver.

A ED caracteriza-se também como um esquema experimental balizada nas relações didáticas em sala de aula, que consiste na concepção, na realização, na observação e nas análises de sequências de ensino (Artigue, 1995). Nesse sentido, justifica-se a escolha da ED, haja vista a diversidade de relações envolvidas na atividade pedagógica. Ademais, Pais (2015, p. 77), ressalta que "a utilização de uma engenharia didática reforça a confiabilidade da pesquisa e sua potencialidade se deve à defesa do vínculo com a realidade da sala de aula".

Almouloud (2007, p. 171), ressalta que a ED "pode ser usada em pesquisas que estudam os processos de ensino e aprendizagem de um dado objeto matemático e, em particular, a elaboração de gêneses cruciais para um dado conceito". Ademais, ela propicia organizar a metodologia para a realização prática da pesquisa promovendo as relações de dependência entre a teoria e a prática.

Segundo Almouloud e Silva (2012, pp 26-27), uma pesquisa pautada nos princípios da ED, divide-se em quatro fases, a saber: 
1. Análise preliminares: considerações sobre o quadro teórico didático geral e os conhecimentos já adquiridos sobre o assunto em questão. Incluem a análise epistemológica do ensino atual e seus efeitos, das concepções dos alunos, dificuldades e obstáculos, e análise do campo das restrições e exigências no qual vai se situar a efetiva realização didática.

2. Concepções e análise a priori das situações didáticas: o pesquisador, orientado pelas análises preliminares, delimita certo número de variáveis pertinentes ao sistema sobre os quais o ensino pode atuar, chamadas de variáveis de comando (microdidáticas ou macrodidáticas).

3. Experimentação: consiste na aplicação da sequência didática, tendo como pressupostos apresentar os objetivos e condições da realização da pesquisa, estabelecer o contrato didático e registrar as observações feitas durante a experimentação.

4. Análise a posteriori e validação: A análise a posteriori consiste em uma análise de um conjunto de dados colhidos ao longo da experimentação, como por exemplo, produção dos alunos, registros de observadores e registro em vídeo. Nessa análise, se faz necessário sua confrontação com a análise a priori para que seja feita a validação ou não das hipóteses formuladas na investigação.

Convém ressaltar que este trabalho utilizou somente as duas primeira fases da ED. Estas serão descritas nas próximas seções, conforme a estrutura estabelecida nesta pesquisa, visto que o intuito é descrever as estratégias e os critérios utilizados para se gamificar o percurso metodológico.

\section{Análise preliminar sobre o processo de extensão da sequência de Padovan}

$\mathrm{Na}$ análise preliminar da ED os aspectos epistemológicos, cognitivos e didáticos do conteúdo matemático são expostos e discutidos, pretendendo realizar um desenvolvimento histórico e evolutivo dos conceitos selecionados (Artigue, 1995). Diante disso, é realizado um levantamento bibliográfico sobre o contexto epistemológico da extensão da sequência de Padovan para números inteiros não positivos, pelos trabalhos de Stewart (1996), Spinadel e Buitrago (2009), Vieira e Alves (2019) e Voet e Schoonjans (2012).

Considerando a epistemologia e o processo histórico, tem-se que a sequência de Padovan é linear e recorrente, de números inteiros e de terceira ordem, considerada como "prima" da conhecida sequência de Fibonacci. O seu nome deve-se ao arquiteto italiano Richard Padovan (1935- ), em que iniciou estudos sobre o número plástico, com o trabalho do holandês Hans Van Der Laan (1904 - 1991). Após isso, Padovan criou então uma sequência em que tivesse como relação de convergência entre os termos vizinhos essa constante plástica (Ferreira, 2015), apresentando algumas definições, conforme Definição 1 e 2.

Definição 1. A fórmula de recorrência da sequência de Padovan, com $P_{0}=P_{1}=P_{2}=1$, é dada por:

$$
P_{n}=P_{n-2}+P_{n-3}, n \geq 3
$$

Definição 2. O polinômio característico da sequência de Padovan é dado pela equação:

$$
x^{3}-x-1=0
$$

Apresentando como resolução três raízes, sendo duas complexas e conjugadas e uma real, conhecida como número plástico onde o seu valor é aproximadamente 1.32 (Voet e Schoonjans, 2012).

Vale ressaltar ainda outros trabalhos referentes à forma matricial desta sequência, encontrados em periódicos de matemática pura, tais como Seenukul (2015) e Sokhuma (2013).

Teorema 1. Para $Q=\left[\begin{array}{lll}0 & 1 & 0 \\ 1 & 0 & 1 \\ 1 & 0 & 0\end{array}\right]$, tem-se que $Q=\left[\begin{array}{lll}P_{n-2} & P_{n-3} & P_{n-4} \\ P_{n-1} & P_{n-2} & P_{n-3} \\ P_{n-3} & P_{n-4} & P_{n-5}\end{array}\right]$ para todo $n \geq 5$.

Demonstração. Utilizando o princípio da indução finita, pode-se facilmente validar o teorema.

A partir desses conceitos matemáticos, foram selecionadas algumas definições e teoremas, com o viés de explorar o processo de extensão da sequência, tendo em vista a transposição didática, visando oportunizar a compreensão e a construção desse conteúdo, instigando o lado indutivo do aluno. Diante disso, são desenvolvidas duas situações-problema com enfoque na TSD na seção seguinte, para a posteriori ser gamificada. 
A segunda etapa da ED, referente a concepção e análise a priori, será explanada na metodologia, visto que esta investigação ambiciona fundamentar os passos de elaboração de uma prática em sala de aula gamificada.

\section{Método}

As etapas metodológicas utilizadas para a gamificação no ensino da sequência de Padovan foram: a) Identificação e análise dos conceitos que serão abordados na aula proposta; b) Desenvolvimento das situações conflitivas sem os elementos da gamificação; c) Implementação de elementos e estrutura da gamificação.

Esta pesquisa possui como público alvo, alunos do nível de graduação na área de Matemática, visto que o assunto de sequências está presente em livros de história da matemática, apresentando uma abordagem vaga de conceitos matemáticos e não tratando de sequências que são consideradas relativamente novas, como é o caso da sequência de Padovan (Alves e Borges Neto, 2011).

A seção seguinte trata da segunda etapa da ED, identificada como: concepção e análise a priori das situações didáticas. Em seguida, apresentar-se-á o delineamento da gamificação das fases da TSD.

\section{Concepções e análise a priori das situações didáticas}

Nesta etapa serão elaboradas duas situações-problema sobre a extensão da Sequência de Padovan para índices inteiros não positivos, fundamentadas da TSD de Brousseau (1986). A TSD tem por finalidade estimular o conhecimento matemático teórico e investigativo dos alunos, através da interação com as fases de ação, formulação, validação e institucionalização.

Situação-problema 1: A sequência de Padovan é uma sequência linear e recorrente de números inteiros de terceira ordem, considerada como prima da sequência de Fibonacci, possuindo ainda um processo histórico conforme estudado por Stewart (1996). A sua fórmula de recorrência, com $P_{0}=P_{1}=P_{2}=1$ é dada pela definição $P_{n}=P_{n-2}+P_{n-3}, n \geq 3$.

Tomando como base os estudos referentes aos números de Fibonacci e a definição apresentada na Situaçãoproblema 1, é possível estabelecer uma outra recorrência, que possa ser utilizada para o cálculo dos termos do lado esquerdo (índice inteiro não positivo) da sequência de Padovan?

Na fase da ação, os discentes deverão realizar tentativas para calcular os termos do lado esquerdo da sequência, com base em seus conhecimentos prévios de Álgebra Linear, a fim de identificar o padrão de recorrência a partir da definição dada. Na situação de formulação, recorrendo à fórmula $P_{n}=P_{n-2}+P_{n-3}, n \geq 3$, os estudantes deverão perceber que, ao substituir o valor de $n<3$ obtém-se então os termos como mostrado na Tabela 2 .

\section{Tabela 2}

Termos da sequência de Padovan com índice inteiro não positivo

\begin{tabular}{cccccccccc}
\hline$P_{-1}$ & $P_{-2}$ & $P_{-3}$ & $P_{-4}$ & $P_{-5}$ & $P_{-6}$ & $P_{-7}$ & $P_{-8}$ & $P_{-9}$ & $P_{-10}$ \\
\hline 0 & 1 & 0 & 0 & 1 & -1 & 1 & 0 & -1 & 2 \\
\hline
\end{tabular}

$\mathrm{Na}$ validação, utilizando os valores encontrados anteriormente, deve-se determinar uma outra recorrência que seja possível obter os termos inteiros não positivos de modo imediato. De acordo com a definição dada na atividade proposta, constata-se que, para calcular os termos negativos, deve haver uma manipulação algébrica. Contudo, espera-se que, após os cálculos algébricos, os discentes alcancem à fórmula $P_{-n}=P_{-n+3}+P_{-n+1}, n \geq 1$ e com $n \in \mathbb{N}$.

Por fim, na institucionalização, o docente retoma para a situação didática proposta, conferindo as resoluções dos estudantes e revelando a intenção da atividade que é obter a extensão da sequência para índices inteiros não positivos.

Situação-problema 2: Uma forma de obter qualquer elemento de uma sequência linear e recursiva é através da matriz geradora Q (Falco e Plaza, 2007). Esta técnica foi aplicada para a sequência de Fibonacci e, nesta atividade, a mesma ideia será aplicada para os números de Padovan. A sequência de Padovan possui uma matriz Q de ordem 3x3, a qual quando elevada a n-ésima potência, pode-se obter os termos desta sem o cálculo da recursividade. A matriz geradora Q da Sequência de Padovan, é dada por (Sokhuma, 2013): 
Para $Q=\left[\begin{array}{lll}0 & 1 & 0 \\ 1 & 0 & 1 \\ 1 & 0 & 0\end{array}\right]$, tem-se que $Q^{n}=\left[\begin{array}{lll}P_{n-2} & P_{n-3} & P_{n-4} \\ P_{n-1} & P_{n-2} & P_{n-3} \\ P_{n-3} & P_{n-4} & P_{n-5}\end{array}\right]$ para todo $n \geq 5$

Encontre a matriz geradora da sequência de Padovan para os termos do lado esquerdo (índice inteiro não positivo) da sequência.

Durante a resolução dessa situação-problema, no momento da ação, os estudantes deverão buscar em seus conhecimentos matemáticos, a propriedade matricial para que seja obtida a inversa da matriz geradora $\mathrm{Q}$, dada na questão $\left(Q Q^{-1}=I\right)$. Na dialética da formulação, espera-se que os estudantes encontrem a seguinte matriz $Q^{-1}=\left[\begin{array}{ccc}0 & 0 & 1 \\ 1 & 0 & 0 \\ 0 & 1 & -1\end{array}\right]$ elevando a n-ésima potência, tem-se $Q^{-n}=\left[\begin{array}{ccc}P_{-n-2} & P_{-n-3} & P_{-n-4} \\ P_{-n-1} & P_{-n-2} & P_{-n-3} \\ P_{-n-3} & P_{-n-4} & P_{-n-5}\end{array}\right]$. Espera-se que essa matriz seja verificada utilizando o princípio da indução finita para $n>0, \operatorname{com} n \in \mathbb{N}$, seguindo, portanto, todos os passos do modelo de demonstração matemático. Com isso, na formalização o docente deverá relatar o objetivo da atividade que é desenvolver a forma matricial da sequência de Padovan para índices inteiros não positivos, obtendo uma forma de encontrar os números da sequência, sem necessitar conhecer os seus termos anteriores.

\section{A gamificação das situações conflitivas da TSD}

Os elementos identificados nas pesquisas de Chou (2015) e Costa et al. (2019) serão implementados na sequência de ensino fundamentada na TSD, conforme o levantamento realizado nas duas etapas da ED. Por se tratar de uma pesquisa descritiva, sem um aplicação prática para coleta de dados, o uso da gamificação com as etapas da TSD, ambiciona-se implementar todos os elementos propostos como um exemplo do uso da gamificação no ensino.

De início identifica-se que alguns pontos apresentam importante relevância para a gamificação de qualquer estratégia de ensino. Estas questões ajudam a direcionar os passos para uma gamificação da sequência metodológica, apresentados na tabela 3:

\section{Tabela 3}

Pontos relevantes para se gamificar uma sequência de ensino

\begin{tabular}{|c|c|}
\hline Pontos relevantes & Descrição dos pontos \\
\hline Quais os objetivos da aula? & $\begin{array}{l}\text { No final da aula o aluno será capaz de compreender os aspectos teóricos } \\
\text { da extensão da Sequência de Padovan para índices inteiros não positivos. }\end{array}$ \\
\hline Qual o público alvo? & Alunos no nível de graduação no ensino de Matemática. \\
\hline Quais os conceitos relacionados? & Sequência de Padovan; sequência de Fibonacci; álgebra linear. \\
\hline Quais os passos da sequência de ensino? & $\begin{array}{l}\text { Passos da TSD: } 1^{\mathrm{a}} \text { Contrato didático; } 2^{\mathrm{a}} \text { Ação; } 3^{\mathrm{a}} \text { Formulação; } 4^{\mathrm{a}} \\
\text { Validação; } 5^{\mathrm{a}} \text { Institucionalização. }\end{array}$ \\
\hline O que se pretende gamificar? & Passos da TSD; situações conflitivas e fenomenológicas \\
\hline Quais os elementos de game serão utilizados? & $\begin{array}{l}\text { Unidades de Chou (2015): Significado épico; Desenvolvimento e } \\
\text { realização; Capacidade de criatividade e feedback; Propriedade e posse; } \\
\text { Influência social e parentesco; Escassez e impaciência; Imprevisibilidade } \\
\text { e curiosidade; e Perda e prevenção. }\end{array}$ \\
\hline
\end{tabular}

Para descrever como a gamificação será implementada nesta proposta, utiliza-se das oito unidades propostas por Chou (2015) e alguns elementos de game apresentados por Costa et al (2019). A primeira unidade, significado épico, será utilizada conforme o aluno compreende a funcionalidade e a importância das descobertas dele sobre a sequência de Padovan para índice inteiro não positivo.

No significado épico o professor pode desenvolver uma história em que no decorrer do enredo podem surgir determinados desafios, e que para salvar um colega ou equipe o aluno precise resolver esse determinado desafio, tornando-se assim o herói da história. Um estilo de jogo muito semelhante com a estratégia de se implementar histórias com desafios é o Role-Playing Games (RPG). Em português, o termo RPG significa 
jogo narrativo ou jogo de interpretação de papéis é um estilo de jogo que os integrantes assumem a posição de um personagem do game. A etapa de validação da TSD é a etapa que mais envolve o conceito de significado épico, pois é nesse momento que o aluno entra em contato com mais profundidade no assunto para verificar se suas hipóteses estavam corretas.

A segunda unidade, desenvolvimento e realização, implementa-se na interação do aluno com os desafios proposto pelo professor, ao desenvolver hipóteses e verificá-las. A vontade de progredir, desenvolver habilidades e superar os desafios podem estar relacionados com a interação social ou simplesmente pelo fato do aluno gostar do assunto e da forma que está sendo trabalhado em sala de aula. Nesse sentido, todas as etapas da TSD podem relacionar-se com esta unidade, visto que o funcionamento das situações didáticas englobam a interação do aluno com as situações conflitivas. Para que o aluno compreenda que está progredindo e desenvolvendo novas habilidades, o professor deve fornecer feedbacks constantes para a turma.

$\mathrm{Na}$ terceira unidade, capacidade de criatividade e feedback, o retorno para o aluno deve ser trabalhado em todas as etapas de uma boa unidade de ensino, pois esse necessita saber se caminha para o lugar correto em suas hipóteses. Os feedback podem ser apresentados para os alunos de forma individual e coletiva, cada uma dessas formas de se apresentar causam uma influência diferente sobre a motivação e participação dos alunos. Cabe ao professor identificar em sua turma a preferência dos alunos, pois cada uma deles apresentam níveis e formas de motivação e engajamento diferentes.

A quarta unidade, propriedade e posse, o professor pode fazer uma separação por equipe e organização das responsabilidades, conforme as habilidade de cada aluno. Nesse sentido, o aluno se compromete com a equipe por se tornar o responsável/dono daquela função conforme suas competências, assim a sensação de posse pode ser extremamente explorada. Além disso, o aluno deve ser livre para escolher a sua posição dentro da equipe, com isso o professor traz um outro elemento contido nos games, que é a voluntariedade (Alves, 2015; Costa et al, 2019).

A quinta unidade, influência social e realização, é utilizada em todas as etapas da TSD, visto que os alunos podem ser divididos em times e com isso a comunicação entre os membros para um bom desempenho é explorado. Para a gamificação, desenvolver uma espécie de hierarquia dentro de cada time ao separar perfis de jogadores, como: líder; suporte; especialista e entre outros, pode ser relevante. Os alunos comprometem-se, socialmente, para um bom desempenho da equipe por conter uma função bem específica, que pode ser sobre a missão de dominar um assunto/território, resolver um problema ou descobrir um segredo para a solução de uma desafios.

A sexta unidade, escassez e impaciência, pode ser explorada quando os alunos trabalham juntos para chegar em um objetivo e adquirir prêmios, poder dentro do jogo, medalhas ou até mesmo um destaque maior dentro da equipe. Se for bem trabalhada, os alunos podem ver o resultado de outras unidades de gamificação como um motor, como é o caso do significado épico, em que os alunos podem almejar a sensação de sentir-se parte de algo maior, simplesmente por não ter tido o prazer de se ver como um herói dentro da história e da sala de aula.

A sétima unidade e a oitava mostram-se para os alunos, por se tratar de estratégias puramente diferenciadas, explorando a curiosidade de saber o que vai vir a seguir. Isso pode ser um fator que os motive e os torne cada vez mais participativos, além de que, o medo de perder a estratégia diferenciada e os resultados que essa estratégia proporciona, podem ser amplamente utilizados pelo professor para motivar a ação dos seus alunos.

É importante salientar que, para a gamificação da sala de aula, não pressupõe o uso sistemático de laboratórios de informática, nem o uso de todos as unidade/elementos de game que foram sugeridos na pesquisa por Chou (2015), Costa et al. (2019) e McGonigal (2017). A seguir será evidenciado, nas considerações finais, a importância da proposta para a comunidade científica, assim, como as propostas de pesquisas que podem ser desencadeadas a partir dos conceitos e sistematização supracitada.

\section{Considerações finais}

Esta pesquisa teve como intuito demarcar elementos representativos da gamificação, conforme os passos da sequência didática TSD, para o ensino de situações conflitivas da extensão da sequência de Padovan para 
índice inteiro não positivo, com alunos no nível de graduação. Para isso, a pesquisa foi organizada conforme a estrutura metodológica da ED ao utilizar as duas primeiras fases (análise preliminar e análise a priori), sem o aprofundamento das etapas de experimentação e validação. Nesse sentido, a presente produção trata-se de uma vertente puramente descritiva, sem a implementação e coleta de dados junto aos alunos.

A gamificação no ensino é direcionada para o engajamento e a motivação dos alunos em atividades em sala de aula. Em se tratando de uma ordem metodológica para a gamificação de percursos metodológicos em sala de aula, observa-se a partir da produção, que ordena-se o delineamento conforme as seguintes etapas: a) Identificação e análise dos conceitos que serão abordados na aula proposta, direcionada para a análise preliminar realizada pela ED; b) Desenvolvimento das situações conflitivas, que ficou a critério da concepção e análise a priori da ED, e por último c) Implementação de elementos e estruturas da gamificação que utilizouse como base as pesquisas de Chou (2015) e de Costa et al. (2019).

De modo geral, a relação proposta entre a gamificação, ED e TSD caracteriza-se como uma proposta relativamente inédita, visto que as etapas se complementam para o ensino de várias áreas e, não somente para um caso específico da sequência de Padovan. Ademais, a gamificação possui a capacidade de ser implementada com percursos metodológicos de ensino para favorecer uma participação mais ativa e colaborativa dos alunos nas atividades desenvolvidas durante as aulas.

Como propostas de pesquisas futuras, evidencia-se a necessidade de se aplicar a perspectiva metodológica delineada neste artigo, visando um aprofundamento nas duas últimas etapas da ED, Experimentação, Análise a posteriori e validação, para verificar se a proposta apresentada possui um papel relevante para o ensino superior em cursos na área de Matemática e posteriormente, sua relevância em uma transposição interdisciplinar.

\section{Referências}

Almouloud, S. A. (2007). Fundamentos da didática da matemática. Curitiba: Editora UFPR.

Almouloud, S. A., \& Silva, M. J. F. (2012). Engenharia didática: evolução e diversidade Didactic engineering: evolution and diversity. Revemat: Revista Eletrônica de Educação Matemática, 7(2), 22-52. https://doi.org/10.5007/1981-1322.2012v7n2p22

Alves, F. (2015). Gamification: como criar experiências de aprendizagem engajadoras. DVS Editora.

Alves, F. R. V., \& Borges Neto, H. (2011). A existência da Sequência de Fibonacci no campo dos Inteiros: uma atividade de investigação apoiada nos pressupostos da Sequência Fedathi. Boletim GEPEM, (59), 135140. http://costalima.ufrrj.br/index.php/gepem/article/view/81/268

Artigue, M. (1995). Ingeniería didáctica. In M. Artigue, R. Douady, L. Moreno, \& P. Gómez (Ed.), Ingeniería didáctica en educación matemática: un esquema para la investigación y la innovación en la enseñanza y el aprendizaje de las matemáticas (pp. 33-59). México: Iberoamérica. https://core.ac.uk/reader/12341268

Brousseau, G. (1986). Fondements et méthodes de la didactique des mathématiques. Recherches en Didactique des Mathématiques, 7(2), 33-115. https://revue-rdm.com/1986/fondements-et-methodes-de-la/

Chou, Y. (2015). Actionable gamification: beyond points, badges and leaderboards. Octalysis Media.

Csikszentmihalyi, M. (1999). A descoberta do fluxo: a psicologia do envolvimento com a vida cotidiana. Editora Rocco.

Costa, D. F. da, Monteiro, J. A., Castro, J. B. de, Coutinho Júnior, A. de L., \& Sales, G. L. (2019). Strategies for the elaboration of a gamed activity script. Research, Society and Development, 8(11), e188111451. https://doi.org/10.33448/rsd-v8i11.1451

Ferreira, R. de C. (2015). Números mórficos [Dissertação de Mestrado não publicada]. Universidade Federal da Paraíba, Brasil. https://repositorio.ufpb.br/jspui/handle/tede/8040

Kapp, K. M. (2012). Games, gamification, and the quest for learner engagement. $T+D$, 66(6), 64-68. https://www.td.org/magazines/td-magazine/games-gamification-and-the-quest-for-learner-engagement

Leal, E. A., Miranda, G. J., \& Carmo, C. R. S. (2013). Teoria da autodeterminação: uma análise da motivação dos estudantes do curso de ciências contábeis. Revista Contabilidade \& Finanças, 24(62), 162-173. https://doi.org/10.1590/S1519-70772013000200007 
McGonigal, J. (2017). A realidade em jogo. Rio de Janeiro: Editora Best Seller.

Pais, L. C. (2015). Didática da Matemática: uma análise da influência francesa. Belo Horizonte: Autêntica.

Ramos, V P. P., \& Marques, J. J. P. (2017). Dos jogos educativos à gamificação. Revista de Estudios e Investigación en Psicología y Educación, Extr.(01), 319-323. https://doi.org/10.17979/reipe.2017.0.01.3005

Ribeiro Jr., P., Munhoz, R., Comiotto, T., \& Oliveira, L. (2017). Do jogo ao game: considerações teóricas e articulações entre game e aprendizagem. Revista de Estudios e Investigación en Psicología y Educación, Extr.(13). https://doi.org/10.17979/reipe.2017.0.13.2301

Seenukul, P. (2015). Matrices which have similar properties to Padovan-Matrix and its generalized relations. SNRU Journal of Science and Technology, 7(2), 90-94. https://ph01.tci-thaijo.org/index.php/snru_journal/ article/view/43656

Silva, J. B., Sales, G. L., \& Castro, J. B. (2019). Gamificação como estratégia de aprendizagem ativa no ensino de Física. Revista Brasileira de Ensino de Física, 41(4). https://doi.org/10.1590/1806-9126-rbef-2018-0309

Silva, J. B., \& Sales, G. L. (2017). Gamificação aplicada no ensino de Física: um estudo de caso no ensino de óptica geométrica. Acta Scientiae, 19(5). http://www.periodicos.ulbra.br/index.php/acta/article/view/3174

Silva, J. B., \& Sales, G. L. (2018). Um panorama da pesquisa nacional sobre gamificação no ensino de Física. Tecnia, 2(1). http://revistas.ifg.edu.br/tecnia/article/view/172

Sokhuma, K. (2013). Padovan q-matrix and the generalized relations. Applied Mathematical Sciences, 7(56), 2777-2780. https://doi.org/10.12988/ams.2013.13247

Spinadel, V. W., \& Buitrago, A. R. (2009). Towards van der Laan's Plastic Number in the Plane. Journal for Geometry and Graphics, 13(2), 163-175. http://www.heldermann-verlag.de/jgg/jgg13/j13h2spin.pdf

Stewart, I. (1996). Tales of a neglected number. Scientific American, 274(6), 102-103. https://www.jstor.org/ stable/24989576

Vieira, R. P. M., \& Alves, F. R. V. (2019). A Sequência de Padovan e o número plástico: uma análise prévia e a priori . Research, Society and Development, 8(8), e26881212. https://doi.org/10.33448/rsd-v8i8.1212

Voet, C., \& Schoonjans, Y. (2012). Benedictine thought as a catalyst for 20st Century liturgical space. Proceedings of the Second International Conference of the European Architectural History Network (pp. 255-261). https://limo.libis.be/primo-explore/fulldisplay?docid=LIRIAS1683918\&context=L\&vid=Lirias \&search_scope $=$ Lirias\&tab $=$ default_tab\&lang=en_US

Fecha de recepción: 1 de noviembre de 2019. Fecha de revisión: 24 de julio de 2020. Fecha de aceptación: 31 de julio de 2020. Fecha de publicación: 1 de diciembre de 2020. 